\title{
Effects of heating/cooling-water temperatures on output power characteristics of forced cooling pulley-type SMA heat-engine
}

\author{
T. Tsuda ${ }^{1}$, C. Nakagawa ${ }^{1}$, Y.Takeda ${ }^{2}$, H. Cho ${ }^{3 *}$ \\ 1 Graduate student of Environmental Engineering, The University of Kitakyushu, Japan \\ 2 Take R\&D, Japan \\ 3 Faculty of Environmental Engineering, The University of Kitakyushu, Japan \\ * Corresponding author: Fax: 81-93-695-3247, e-mail: h-cho@kitakyu-u.ac.jp
}

\begin{abstract}
In this research, the effects of heating/cooling water temperatures of a heat engine on the output characteristics of the forced cooling pulley-type SMA heat-engine is investigated for the purpose of operating temperature optimization of the engine. The engine output increases almost linearly as the heating water temperature $\left(T_{\mathrm{H}}\right)$ rises. On the other hand, the engine output shows a gradual decrease as the temperature of SMA element during cooling $\left(T_{\mathrm{SMA}}\right)$ rises to $321.4 \mathrm{~K}$ and then an abrupt decrease when the $T_{\mathrm{SMA}}=322.7 \mathrm{~K}$. Thermal cycling tests under constrained strain conditions for the SMA element were carried out to investigate the effect of heating/cooling temperatures to generation stress $(\Delta \sigma)$ and reaction velocity $\left(V_{\mathrm{R}}\right)$ of the SMA element. In result, $\Delta \sigma$ increases gradually with the increase of $T_{\mathrm{H}}$. Besides, $V_{\mathrm{R}}$ increases almost linearly as $T_{\mathrm{H}}$ increases. This result suggests that the increase of engine output as $T_{\mathrm{H}}$ increases is mainly due to the increase of the $V_{\mathrm{R}}$. Meanwhile, $V_{\mathrm{R}}$ increases gradually with the increase of $T_{\mathrm{SMA}}$. Besides, $\Delta \sigma$ increases as $T_{\mathrm{SMA}}$ rise up to $318 \mathrm{~K}$, above which it decreases rapidly. From these results, it may be concluded that the contributing factor to the engine output is the variation of $\Delta \sigma$ and $V_{\mathrm{R}}$ with the variation of $T_{\mathrm{SMA}}$.

Key words: Shape Memory Alloy, Heat Engine, Ti-Ni-Cu Alloy, Reaction velocity
\end{abstract}

\section{INTRODUCTION}

For the purpose of recovering low temperature exhaust heat (less than $373 \mathrm{~K}$ ), a pulley-type heat-engine using shape memory alloy (SMA) had been manufactured and studied ${ }^{[1,2]}$. This choice of SMA was decided upon because the transformation temperature of Ti-Ni based SMAs are in the temperature range near/below room temperature ${ }^{[3,4]}$, and Ti-Ni based SMAs show a large recovery force (approximately $10^{6} \mathrm{~J} / \mathrm{m}^{3}$ ) ${ }^{[5]}$. However, the product life cycle (PLC) of the previous SMA heat-engine was too short to be of practical use.

In order to improve the PLC of the SMA heat-engine,

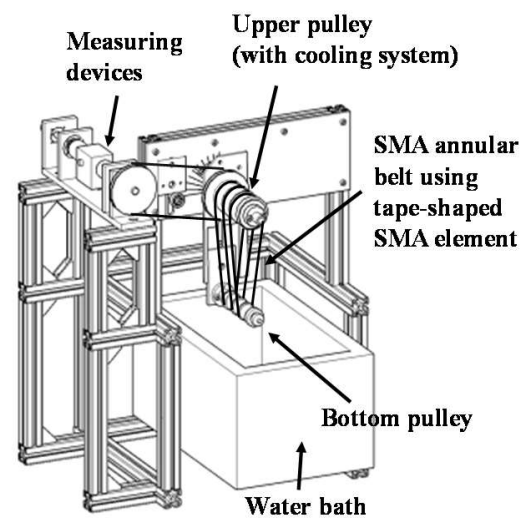

Fig.1 The schematic drawing of pulley-type SMA heat-engine including an idler wheel with cooling system. we proposed to use a tape-shaped SMA element instead of the wire or coil shaped SMA element ${ }^{[6]}$. Furthermore, for the purpose of improving the heat transfer efficiency, we have manufactured a pulley type SMA heat-engine with a forced cooling system using a tape-shaped SMA element, as shown in Fig. $1^{[7,8]}$. This system is consisted of a pulley with a forced cooling system (upper pulley), a normal pulley (bottom pulley), a water bath and measuring devices (torque meter, etc). The pulley with the forced cooling system is cooled down by cooling water, and the water in the water bath is heated and stirred to maintain a constant temperature. Thus, the SMA element is heated and cooled by the heating water in the water bath and the cooling water in the upper pulley, respectively. For this reason, this engine can control the heating/cooling temperature of SMA element by controlling the heating/cooling water temperatures. Moreover, the installation condition (inter-shaft distance and installation angle) of this system can be adjusted. The effect of the installation condition on the output characteristics of this pulley-type SMA heat-engine has already been investigated ${ }^{[8]}$. In this study, the effects of heating/cooling water temperatures of the heat engine on

Table.1 Transformation temperatures of heattreated $\mathrm{Ti}-\mathrm{Ni}-\mathrm{Cu}$ specimen measured by DSC.

\begin{tabular}{cccc}
\hline \multicolumn{4}{c}{ Transformation temperature $(\mathrm{K})$} \\
\hline$M_{\mathrm{s}}$ & $M_{\mathrm{f}}$ & $A_{\mathrm{s}}$ & $A_{\mathrm{f}}$ \\
\hline 320.1 & 306.3 & 328.4 & 341.5 \\
\hline
\end{tabular}


the output characteristics of the engine are investigated for the purpose of operating temperature optimization of this forced cooling pulley-type SMA heat-engine.

\section{EXPERIMENTAL METHOD}

\subsection{Tape-shaped SMA element}

The chemical composition of the tape-shape SMA used in this study is Ti-45Ni-5Cu (at\%). The width, thickness and length of the tape-shaped SMA for the driving element of SMA engine are $9.5 \mathrm{~mm}, 0.12 \mathrm{~mm}$ and 380 $\mathrm{mm}$ respectively. The driving element for the SMA engine is a SMA specimen heat-treated at $673 \mathrm{~K}$ for 3.6 $\mathrm{ks}$ in the atmosphere while wound around a stainless steel pipe with a $15 \mathrm{~mm}$ diameter. And then, the SMA specimen is welded at the leader and end parts to make an annular tape-shaped SMA. Table.1 shows transformation temperatures of a heat-treated specimen measured by a differential scanning calorimetry (DSC).

\subsection{Pulley-type SMA heat-engine including the idler} wheel with a cooling system

The diameter of the upper and bottom pulley of the SMA heat-engine (as shown in Fig.1) are $78 \mathrm{~mm}$ and $25 \mathrm{~mm}$ respectively. The distance in a straight line between the center of upper pulley and bottom pulley is set at $105 \mathrm{~mm}$. The angle formed by the straight line passing through the center of each pulley and the hot-water surface is set at 90 deg. The SMA annular belt made of the tape-shaped SMA is installed over both these pulleys. The SMA elements are heated by immersing the bottom pulley in hot water inside the water bath, and then the engine operates by the shape recovery force of the SMA elements. The output power of this engine is transmitted to the output measuring device by the power transmission belt attached to the upper pulley. The constant load for torque measurement is generated by the electric motor. Temperatures of the heating water $\left(T_{\mathrm{H}}\right)$ and cooling water $\left(T_{\mathrm{C}}\right)$ are varied from $343 \mathrm{~K}$ to $363 \mathrm{~K}$ and from $293 \mathrm{~K}$ to $313 \mathrm{~K}$, respectively.

\subsection{Thermal cycling tests under constrained strain condition}

In order to investigate the effect of the heating/cooling temperatures on the output characteristics of SMA element, thermal cycling tests under constrained strain condition for SMA element were carried out. Fig.2 and Fig. 3 show schematic drawings of thermal cycling tests under constrained strain condition and the stress-strain curve in the thermal cycling test under constrained strain condition, respectively. The width, thickness and length of the tape-shaped SMA for thermal cycling tests are 9.5 $\mathrm{mm}, 0.12 \mathrm{~mm}$ and $50 \mathrm{~mm}$ respectively. In addition, this SMA specimen is heat-treated at $673 \mathrm{~K}$ for $3.6 \mathrm{ks}$ in the atmosphere for the shape-memory treatment for achieving linear shape. The SMA element was loaded to the given $1.2 \%$ pre-strain in the cooled oil bath, as shown in Fig.2(a) (Fig.3 (a) A $\rightarrow$ B). The $1.2 \%$ strain is the maximum applied strain during an engine operation. The cooled oil temperature $\left(T_{\mathrm{CO}}\right)$ is controlled within the range of $T_{\mathrm{C}}$ mentioned at 2.2. And then, the specimen is immersed in the heated oil bath as shown in Fig.2 (b). The heated oil temperature $\left(T_{\mathrm{HO}}\right)$ is controlled [at the range of within the range of $T_{\mathrm{H}}$ mentioned at 2.2. Since the stress increases due to the austenitic transformation (Fig.3 (a) B'

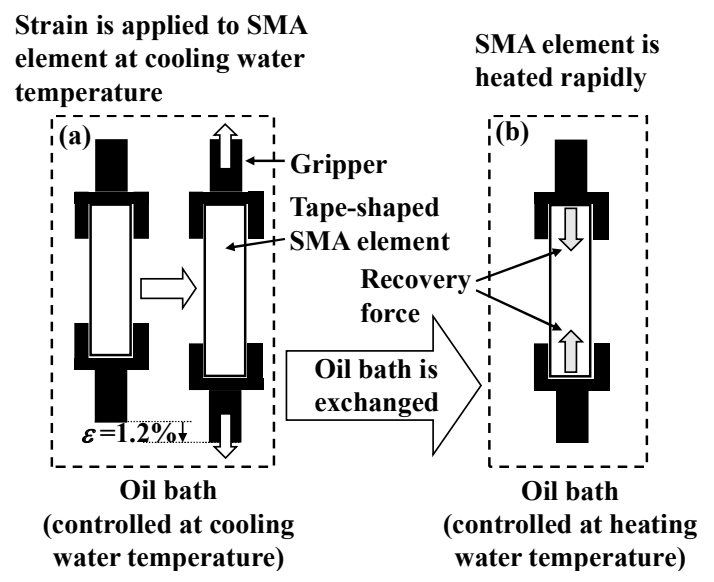

Fig.2 Schematic drawings of thermal cycling tests under constrained strain condition.

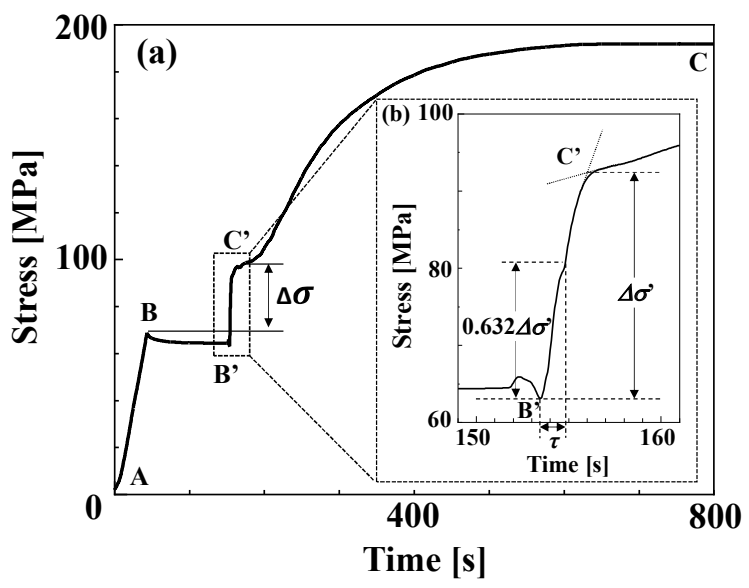

Fig. 3 The stress-strain curve in the thermal cycling test under constrained strain condition.

$\rightarrow \mathrm{C}$ ), the specimen was heated rapidly under constrained conditions. In this study, the stress difference between the maximum stress at $T_{\mathrm{C}}$ and the stress that rapidly increased linearly by heating is defined as the generation stress $(\Delta \sigma)$ Moreover, to investigate the reaction velocity of SMA element, the time constant $(\tau)$ is defined. Fig.3 (b) shows the enlarged view of the (a) heating part of the stressstrain curve. The stress difference between the heating start (B') and the endpoint of the linear stress increase (C') is defined as the $\Delta \sigma^{\prime}$, and the time constant $(\tau)$ is the period from the heating start time to the arrival time of the stress reaching $0.632 \Delta \sigma^{\prime}(1-\exp (-1) \cong 0.632)$. In this study, the reaction velocity of the heated SMA element $\left(V_{\mathrm{R}}\right)$ is expressed as the reciprocal of $\tau$.

\section{RESULTS AND DISCUSSION}

3.1 Effects of heating/cooling-water temperatures on engine output of SMA heat-engine

Figure 4 shows the relationship between engine output and $T_{\mathrm{H}}$, when the $T_{\mathrm{C}}=293 \mathrm{~K}$. The engine output increases almost linearly as $T_{\mathrm{H}}$ rises. Fig. 5 shows the relationship between the engine output and $T_{\mathrm{C}}$, when the $T_{\mathrm{H}}=363 \mathrm{~K}$. The engine output shows a gradual decrease up to $308 \mathrm{~K}$ and then an abrupt decrease when the $T_{\mathrm{C}}=308 \mathrm{~K}$. In this experiment, the SMA element makes contact with the heating water directly, but does not make contact with the 


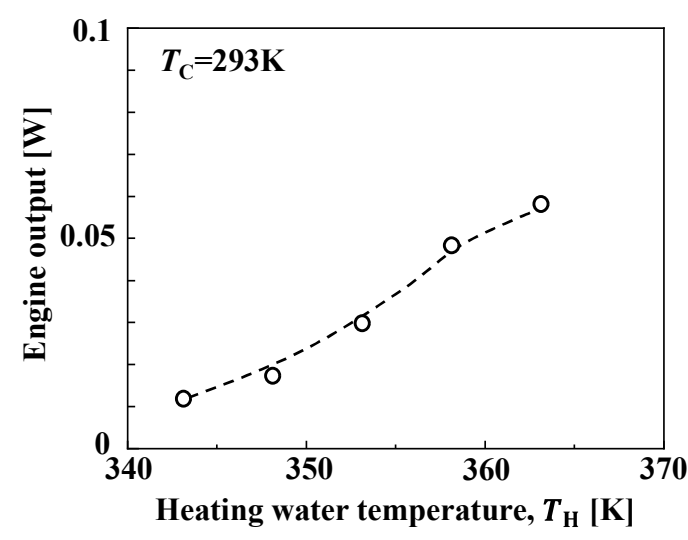

Fig. 4 The relationship between engine output and $T_{\mathrm{H}}$, when the $T_{\mathrm{C}}=293 \mathrm{~K}$.

cold cooling water directly. Therefore, it is thought that the temperature of SMA element is almost equal to the $T_{\mathrm{H}}$ when the SMA is heated, but the temperature of the SMA element is not equal to the $T_{\mathrm{C}}$ when the SMA is cooled. For this reason, the temperature of SMA element during cooling $\left(T_{\mathrm{SMA}}\right)$ is determined by thermographic measurement, and the relationship between engine output and $T_{\mathrm{SMA}}$ was investigated. Fig. 6 shows the relationship between engine output and $T_{\mathrm{S}} \mathrm{AA}$. The $T_{\mathrm{S} M A}$ varies form $314.4 \mathrm{~K}$ to $324.3 \mathrm{~K}$. The engine output shows a gradual decrease up to $321.4 \mathrm{~K}$ and then an abrupt decrease. In addition, the inflection point temperature exists in the vicinity of $M_{\mathrm{s}}$.

These tendencies are thought to be caused by the variation of generation stress $(\Delta \sigma)$ and reaction velocity $\left(V_{\mathrm{R}}\right)$ of the heated SMA element with the variation of $T_{\mathrm{H}}$ and $T_{\mathrm{C}}$. Accordingly, to investigate the effects of $T_{\mathrm{H}}$ and $T_{\mathrm{C}}$ on $\Delta \sigma$ and $V_{\mathrm{R}}$ of SMA element, thermal cycling tests under constrained strain condition were carried out.

3.2 Effects of heating/cooling temperatures on generation stress and reaction velocity of SMA element

Figure 7 shows relationships between $\Delta \sigma$ and $V_{\mathrm{R}}$ of the heated SMA element and $T_{\mathrm{HO}}$, when the $T_{\mathrm{CO}}=293 \mathrm{~K}$. The $\Delta \sigma$ shows a sharp rise at $343 \mathrm{~K}$, and it increases gradually up to $363 \mathrm{~K}$, above which it is saturated. On the other

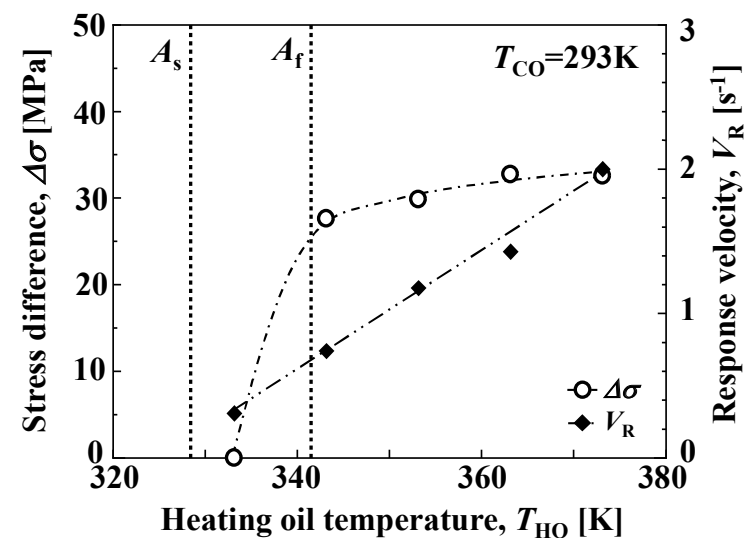

Fig.7 Relationships between $\Delta \sigma$ and $V_{\mathrm{R}}$ of heated SMA element and $T_{\mathrm{HO}}$, when the $T_{\mathrm{CO}}=293 \mathrm{~K}$.

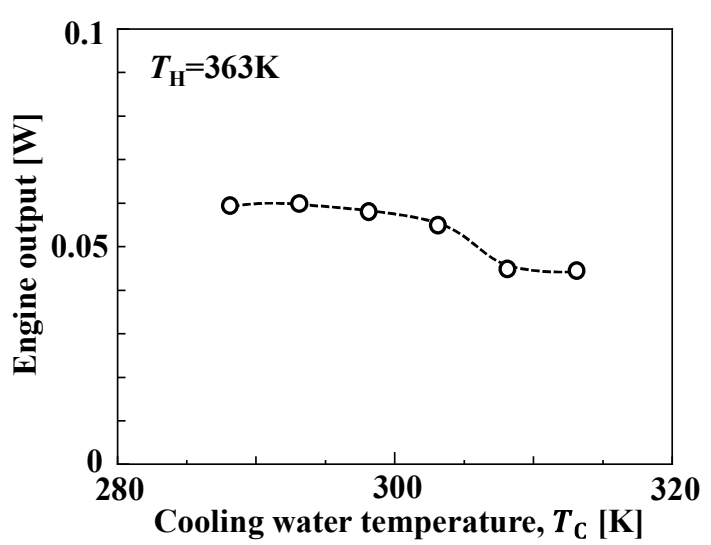

Fig.5 The relationship between engine output and $T_{\mathrm{C}}$, when the $T_{\mathrm{H}}=363 \mathrm{~K}$.

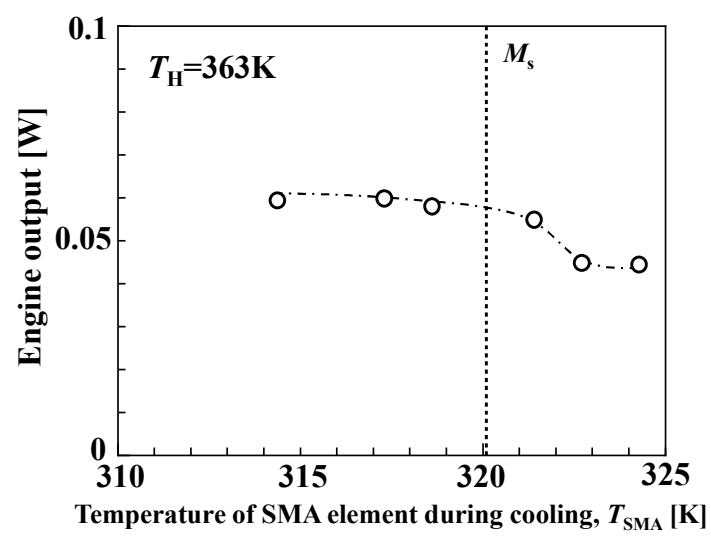

Fig.6 The relationship between engine output and $T_{\mathrm{SmA}}$, when the $T_{\mathrm{C}}=293 \mathrm{~K}$.

hand, the $V_{\mathrm{R}}$ increases almost linearly as temperature rises. From these results, the variation of engine output with the variation of $T_{\mathrm{H}}$ is thought to be mainly caused by the variation of $V_{\mathrm{R}}$ with the increase of $T_{\mathrm{H}}$. Fig.8 shows the explanatory drawing of the variation of $\Delta \sigma, V_{\mathrm{R}}$ and engine output with $T_{\mathrm{H}}$. The temperature dependence of $\Delta \sigma$ is weaker than that of $V_{\mathrm{R}}$, when the $T_{\mathrm{H}}$ is above $340 \mathrm{~K}$. Therefore, the engine output increases almost linearly as temperature rises. From these results, it is concluded that the higher the $T_{\mathrm{H}}$, the higher engine output.

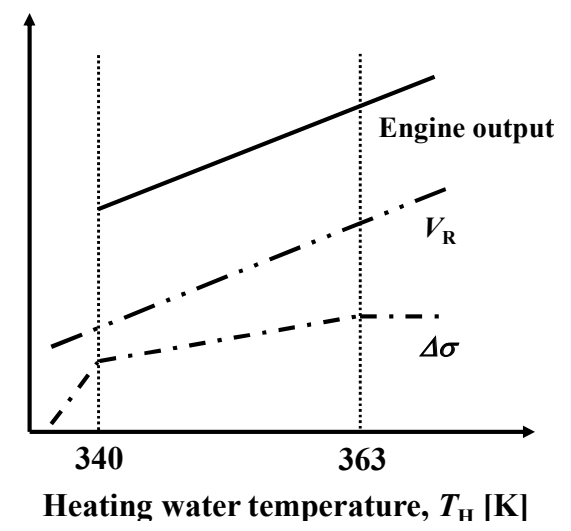

Fig. 8 The explanatory drawing of the variation of $\Delta \sigma, V_{\mathrm{R}}$ and engine output with $T_{\mathrm{H}}$. 


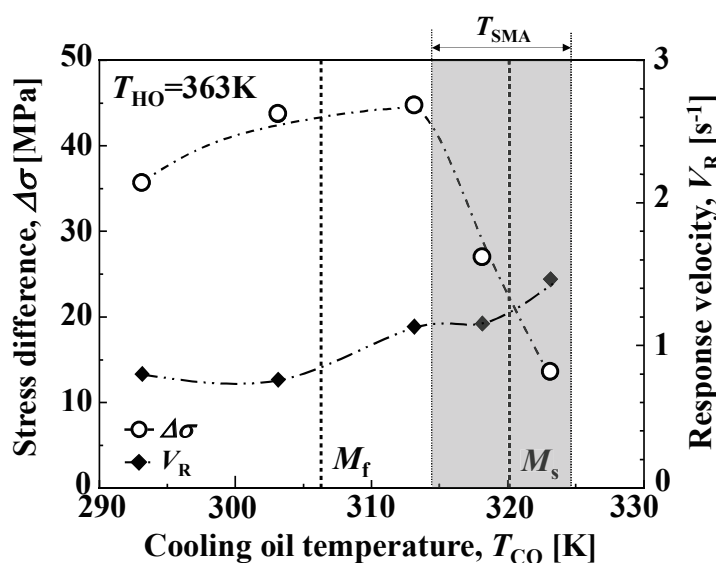

Fig.9 Relationships between $\Delta \sigma$ and $V_{\mathrm{R}}$ of heated SMA element and $T_{\mathrm{CO}}$, when the $T_{\mathrm{HO}}=363 \mathrm{~K}$.

Figure 9 shows relationships between $\Delta \sigma$ and $V_{\mathrm{R}}$ of the heated SMA element and $T_{\mathrm{CO}}$, when the $T_{\mathrm{HO}}=363 \mathrm{~K}$. The $\Delta \sigma$ increases as temperature rises up to $313 \mathrm{~K}$, above which it decreases rapidly. In contrast, the $V_{\mathrm{R}}$ is almost constant as the temperature rises up to $303 \mathrm{~K}$, and then it increases with the increase of temperature. From these results, the variation of engine output with the variation of $T_{\mathrm{SMA}}$ is thought to be caused by the combined factors (which is) of the variation of $\Delta \sigma$ and $V_{\mathrm{R}}$ with the increase of $T_{\mathrm{S} M A}$. Fig. 10 shows the explanatory drawing of the variation of $\Delta \sigma, V_{\mathrm{R}}$ and engine output with $T_{\mathrm{S} M A}$. Since $\Delta \sigma$ and $V_{\mathrm{R}}$ are almost constant up to $313 \mathrm{~K}$, the engine output is almost constant up to $313 \mathrm{~K}$. However, the $\Delta \sigma$ decreases with the increase of $T_{\mathrm{SMA}}$ when the $T_{\mathrm{SMA}}$ is above $313 \mathrm{~K}$. In contrast, the $V_{\mathrm{R}}$ increases when the $T_{\mathrm{SMA}}$ is $318 \mathrm{~K}\left(\cong M_{\mathrm{s}}\right)$. Therefore, the engine output is approximately constant as $T_{\mathrm{SMA}}$ rises up to $M_{\mathrm{s}}$. Furthermore, the $V_{\mathrm{R}}$ is almost constant when the $T_{\mathrm{SMA}}$ is from $320 \mathrm{~K}$ to $323 \mathrm{~K}$, and then the engine output drops. Moreover, the engine output becomes constant again when the $T_{\text {SMA }}$ is above $323 \mathrm{~K}$ because the $V_{\mathrm{R}}$ increases again when the $T_{\mathrm{SMA}}$ is above $323 \mathrm{~K}$. From these results, it is desirable that the SMA element be cooled down to a temperature $M_{\mathrm{s}}$ for the increase of engine output.

\section{CONCLUSION}

The effect heating/cooling-water temperatures on output power characteristics of forced cooling pulley-type heatengine using a tape-shaped SMA element were investigated. The obtained results are summarized as follows:

(1) The engine output of the SMA heat-engine increases almost linearly as the temperatures of the heating water $\left(T_{\mathrm{H}}\right)$ rises. On the other hand, the engine output shows a gradual decrease as the temperatures of the cooling water $\left(T_{\mathrm{C}}\right)$ rises up to $303 \mathrm{~K}$, and then an abrupt decrease when the $T_{\mathrm{C}}=308 \mathrm{~K}$.

(2) The temperature of the SMA element during cooling $\left(T_{\mathrm{SMA}}\right)$ is determined by thermographic measurement, and the relationship between engine output and $T_{\mathrm{SMA}}$ was investigated. In result, the engine output shows a gradual decrease as $T_{\text {Sma }}$ rises up to $321.4 \mathrm{~K}$, and then an abrupt decrease when the $T_{\mathrm{SMA}}=322.7 \mathrm{~K}$.

(3) Thermal cycling tests under constrained strain

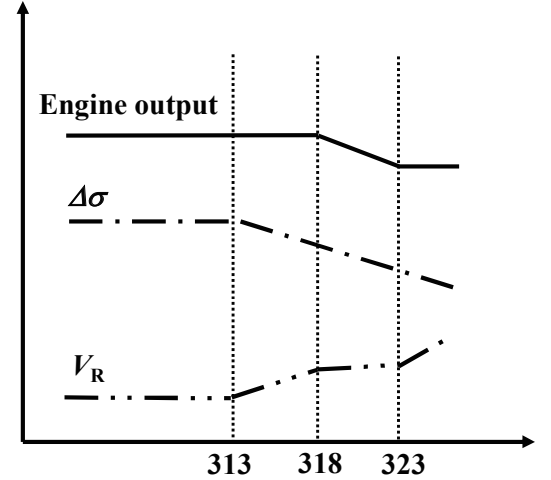

Temperature of SMA element during cooling, $T_{\text {SMA }}[\mathrm{K}]$

Fig. 10 The explanatory drawing of the variation of $\Delta \sigma, V_{\mathrm{R}}$ and engine output with $T_{\mathrm{S} M A}$.

conditions for the SMA element were carried out to investigate the effect of heating/cooling temperatures on generation stress $(\Delta \sigma)$ and reaction velocity $\left(V_{\mathrm{R}}\right)$ of the SMA element. In the results, it was observed that $\Delta \sigma$ increases gradually with the increase of $T_{\mathrm{H}}$. Besides, $V_{\mathrm{R}}$ increases almost linearly as $T_{\mathrm{H}}$ increases. This result suggests that the increase of engine output as $T_{\mathrm{H}}$ increases is mainly due to the increase of $V_{\mathrm{R}}$ of SMA element, and it is concluded that the higher the $T_{\mathrm{H}}$, the higher the engine output is.

(4) $V_{R}$ increases gradually with the increase of $T_{\mathrm{S} M A}$. Besides, $\Delta \sigma$ increases as $T_{\mathrm{SMA}}$ rise up to 318 $\mathrm{K}\left(\cong M_{\mathrm{S}}\right)$, above which it decrease rapidly. From these results, it is concluded that the contributing factor of the relationship of $T_{\mathrm{C}}$ and the engine output is due to the variation of $\Delta \sigma$ and $V_{\mathrm{R}}$ with the variation of $T_{\mathrm{SMA}}$, and it is desirable that the SMA element is cooled down to a temperature $M_{\mathrm{S}}$ for the increase of engine output.

\section{ACKNOWLEDGEMENTS}

This work was supported by Steel Foundation for Environmental Protection Technology (2017, No.56).

\section{REFERENCES}

[1] AD. Johnson, Record of the 10th Intersociety Energy Conversion and Engineering Conference, Newark, DE: 530-534 (1975).

[2] T. Honma, Jour. Jpn, Soc. Mech, Eng., 87, 517-522 (1984).

[3] AR. Pelton, J. Dicello, S. Miyazaki, Minimally Invasive Therapy \& Allied Technologies, 9[2], 107-118 (2000).

[4] J. Frenzel, EP. George, A. Dlouhy, C. Somsen, MF-X Wagner, G. Eggeler, Acta Mat., 58, 3444-3458 (2010).

[5] K. Tsuchiya, ST. Davies, Nanotechnology, 9[2], 6771 (1998).

[6] H. Cho, M. Senju, Y. Takeda, T. Yamamoto and T, Sakuma, Trans. Mat. Res. Soc. Japan, 38[3], 423-426 (2013).

[7] H. Fujiki, C. Nakagawa, Y. Takeda, H. Cho., Trans. Mat. Res. Soc. Japan, 41[3], 285-288 (2016).

[8] C. Nakagawa, H. Fujiki, H. Cho., Trans. Mat. Res. Soc. Japan, 42[3], 69-72 (2017).

(Received January 22, 2018; Accepted February 28, 2018; Published Online April 1, 2018) 